\title{
Epistemological Pluralism: Reorganizing Interdisciplinary Research
}

\author{
$\underline{\text { Thaddeus R. Miller }}^{1}$, Timothy D. Baird ${ }^{2}$, Caitlin M. Littlefield ${ }^{3}$ Gary Kofinas $^{4}, \underline{\text { F. Stuart Chapin III }}^{4}$, and \\ $\underline{\text { Charles L. Redman }}^{1}$
}

\begin{abstract}
Despite progress in interdisciplinary research, difficulties remain. In this paper, we argue that scholars, educators, and practitioners need to critically rethink the ways in which interdisciplinary research and training are conducted. We present epistemological pluralism as an approach for conducting innovative, collaborative research and study. Epistemological pluralism recognizes that, in any given research context, there may be several valuable ways of knowing, and that accommodating this plurality can lead to more successful integrated study. This approach is particularly useful in the study and management of social-ecological systems. Through resilience theory's adaptive cycle, we demonstrate how a focus on epistemological pluralism can facilitate the reorganization of interdisciplinary research and avoid the build-up of significant, but insufficiently integrative, disciplinary-dominated research. Finally, using two case studies - urban ecology and social-ecological research in Alaska-we highlight how interdisciplinary work is impeded when divergent epistemologies are not recognized and valued, and that by incorporating a pluralistic framework, these issues can be better explored, resulting in more integrated understanding.
\end{abstract}

Key Words: adaptive cycle; epistemology; interdisciplinary

\section{INTRODUCTION}

"There is a story-which if it is not true should be-that a certain old lady derived a great spiritual comfort from believing that the word "Mesopotamia" had a profoundly pious significance. When in sore straits, she would prayerfully repeat this momentous word to herself and find new courage to go on. Interdisciplinary research, as a slogan, has acquired something like the intrinsic merit which this old lady imputed to Mesopotamia.” (Wohl 1955)

The call for interdisciplinary research to address linked social and environmental issues is not new (Evans 1951, Wohl 1955). Currently, the drive toward interdisciplinary research is intensifying as universities and research centers struggle to fill gaps in knowledge about the behavior and management of social-ecological systems (SES) that require a fully integrated approach. In an era of rapidly changing social-ecological relationships, traditional research and education programs entrenched in strictly disciplinary approaches are increasingly ill equipped to address a multitude of issues that cut across multiple academic divides (CoFIR et al. 2005). Despite progress in interdisciplinary research, many efforts are hampered by a host of problems, including a tendency to privilege a single epistemological and disciplinary perspective. Different disciplines carry with them different epistemologies, or theories of knowledge. That is, each may have a different conception of what constitutes knowledge, how it is produced, and how it should be applied (Rescher 2003). The privileging of a single disciplinary or single epistemological perspective limits the potential variety of scientific and local knowledge that can contribute to our understanding.

Epistemologies drive presumptions about the "relationship between the researcher and the system/object of study and modeling of system processes" (MacMynowski 2007). They shape how researchers answer questions regarding the validity of knowledge (qualitative vs. quantitative, etc.), the legitimacy of methods to produce knowledge

\footnotetext{
${ }^{1}$ Arizona State University, ${ }^{2}$ University of North Carolina at Chapel Hill, ${ }^{3}$ University of Wisconsin-Madison, ${ }^{4}$ University of Alaska Fairbanks
} 
(experimentation, induction, hypothesis testing, etc.), and the assumptions inherent in particular conceptualizations of the object of study and certain methodologies. The degree to which the answers to these and other questions are similar or divergent can deeply affect interdisciplinary research.

The authors of this paper, representing the disciplines of anthropology, ecology, environmental philosophy, geography, mathematics, and policy science, share an interest in crossing these divides to invigorate the creation of knowledge for the study and management of sustainable SESs. ${ }^{\dagger}$ We suggest that bridging the gaps between disciplinary perspectives demands more active engagement with the norms and processes of science in the development of interdisciplinary research. We propose a reorganization of interdisciplinary research, which we will refer to as epistemological pluralism (Healy 2003, Miller and Erickson 2006), that we hope will lead to the production of more useful scientific knowledge for the study and management of SESs.

We first argue that most academic knowledge production remains, at present, entrenched in strictly disciplinary approaches. Despite decades of attempts to encourage interdisciplinarity, many stakeholders are holding on to a system framed by disciplinary boundaries. Following this, we examine the philosophical foundation for epistemological pluralism, examining the tensions between different epistemologies. With an eye toward the real-world challenge of sustainability, we then present a way of reorganizing research in an academic setting on a philosophical and practical level that may be applied across many scalesindividual researchers, research projects, disciplines, etc. We focus on epistemological pluralism and an iterative process of negotiating values, epistemologies, and knowledge using resilience theory's adaptive cycle as a conceptual framework. Drawing on our own experiences in urban long-term ecological research and social-ecological research in Alaska, we demonstrate how well-intentioned efforts toward interdisciplinary research have served to privilege one epistemology over another in question formulation and research, and how a reorganization based on epistemological pluralism might lead to the production of more fully integrated knowledge.

\section{DISCIPLINARITIES}

In Table 1, we sketch a typology of three epistemologies that may be present in a given research project. These metaphors are meant to illustrate the spectrum of the forms of knowledge and the ways in which they are acquired and validated. Being metaphors, they are idealized and debatable. We welcome dialogue to create a more complete vision of the knowledges present in various research projects.

These metaphors describe the ways in which a given epistemic community (Lee 1993) may acquire knowledge and how it is valued and validated. Within any disciplinary approach, there will be people who span parts of the spectrum. A natural scientist may readily embrace that knowledge is contingent whereas a social scientist may maintain that knowledge should be mechanistic. When separated, these models are seen as providing complete explanations for knowledge and its acquisition. However, when looked at together, it is clear that each provides a different perspective, complementing each other and resulting in a more complete description of knowledge than any of the three could alone.

Each of these metaphors, as well as the communities they represent, also share a set of values that influence and enable the production of knowledge and help establish a common object of inquiry. For example, in an SES, the object of inquiry is not just nature, but nature under a specific description, e.g., mechanistic, a complex adaptive system, constructed (Longino 1990). Before any knowledge is produced or research performed, the subject matter or object/system of inquiry must be characterized "in ways that make certain kinds of explanation appropriate and others inappropriate" (Longino 1990). A given scientific community does not just want knowledge, but knowledge about a particular set of things. Such cognitive aims are not decided upon by the individual; rather, they are negotiated within a set of unquestioned social institutions (rules) that are underpinned with ideological perspectives, such as a discipline.

Disciplinary researchers are characterized by a shared and, to a certain extent, bounded way of apprehending the world. Whereas any given discipline is dynamic and composed of different theoretical and methodological approaches, it will tend to share a language, a set of tools, and 
Table 1. Metaphors of knowledge.

\begin{tabular}{lll}
\hline \hline Knowledge as mechanistic & Knowledge as contingent & Knowledge as narrative \\
\hline $\begin{array}{ll}\text { Believed to be objective, replicable. } \\
\text { Knowledge acquired via the "scientific } \\
\text { method;" sought to demonstrate causality } \\
\text { and allow for prediction. }\end{array}$ & $\begin{array}{l}\text { Importance of agent and context. } \\
\text { Knowledge seeks causality; relies on } \\
\text { behavior, variability, and relation to } \\
\text { socially held norms. }\end{array}$ & $\begin{array}{l}\text { Interpretive and critical. Knowledge is } \\
\text { inherent to object and represents values } \\
\text { that may be shared or individually } \\
\text { held. }\end{array}$ \\
Nature as mechanistic. & Nature as a complex adaptive system. & Nature as constructed. \\
\hline
\end{tabular}

epistemological commitments (Petts et al. 2008, Reich and Reich 2006). Multidisciplinary research arises when multiple researchers investigate a single problem, but do so as if each were working within their own disciplinary setting. In this situation, individual researchers consider a common set of issues, but maintain disciplinary boundaries at the expense of meaningful integration with researchers from different backgrounds. We might call these "epistemological silos," where individuals work from their own epistemological perspective and seek to acquire and validate knowledge within that epistemology. By preserving these disciplinary perspectives, the subsystems of interest to the individual researchers are the objects of study, and there is minimal recognition of a larger, integrated system that exhibits complex relationships between the subsystems themselves. Integration is achieved by "stapling together" the research product. This is not to say that disciplinary knowledge has not contributed to problem solving; it certainly has and will continue to evolve to do so. Our assertion is that there are also important problems that disciplines have not effectively solved.

Interdisciplinary research incorporates a greater degree of integration than either disciplinary or multidisciplinary research. Unified problem formulation, sharing of methods, and perhaps the creation of new questions are aspects of this type of work (Eigenbrode et al. 2007). In addition, interdisciplinary work often has an applied orientation (Thompson Klein 1996). However, most interdisciplinary research ends up entitling a single discipline or epistemology, incorporating others in a support or service role-we can refer to this as "epistemological sovereignty" (Healy 2003). For instance, if an ecologist formulates the research questions for a project and only later invites a social scientist as a service to the investigation, the research typically remains framed by ecological theory, limiting the scope of the social scientist's input. In this case, the inclusion of the social scientist explicitly indicates that the system under study is more complex than the one originally envisioned by the ecologist. As a result, the structure of the project must be re-evaluated, beginning with the choice of the research questions, to reflect this complexity. Without this re-evaluation, the project is likely to maintain a separation between the ecological and social systems, and thus is only multidisciplinary in scope.

Transdisciplinary research transcends entrenched categories to formulate problems in new ways. Collaborators may accept an epistemological perspective unique to the effort, redrawing the boundaries between disciplinary knowledges (Roux et al. 2006, Eigenbrode et al. 2007). Transdisciplinary research is often, although not always, characterized by an explicit engagement with society.

In multidisciplinary, interdisciplinary, and transdisciplinary research, values and a common conception of the object/system of inquiry are rarely articulated and shared. The object of inquiry is often defined by one discipline, thereby entitling their methodological approach and epistemology, imposing a particular set of values - epistemological sovereignty. The move toward integrated research is often motivated by the realization that any single way of knowing is insufficient for understanding the complexity of the world (and, in our case, coupled SESs). Clearly, epistemological sovereignty runs counter to this goal. How then might we take the insights regarding the role of epistemologies in the production of knowledge and apply them to the 
ways in which we organize interdisciplinary research?

To move the practice of interdisciplinary inquiry forward, we argue that scholars, educators, and practitioners need to rethink critically how interdisciplinary research and training can be conducted in the context of "epistemological pluralism" (Healy 2003, Miller and Erickson 2006). We choose to use SESs in this paper as an example of the power of epistemological pluralism: focusing on coupled SESs provides insights that cannot be gained when social and ecological systems are viewed independently; epistemological pluralism is necessary to examine fully the complexity of these linked systems. Epistemological pluralism contributes four crucial elements to the practice of interdisciplinary inquiry. First, it acknowledges the validity and value of multiple ways of knowing. Second, it asserts that integrating these epistemologies results in a more complete understanding of complex issues, such as the sustainability of SESs (Liu et al. 2007). Third, it accepts that operationalizing these different approaches may require continual negotiations. Finally, it requires that disciplinary researchers work together to find ways to accommodate each others' approaches rather than compromise them. This last point in particular requires both an attention to collaborative processes and a certain set of skills to enable group introspection. These should not be considered value-added skills as they are just as fundamental to any collaborative process, be it interdisciplinary or otherwise. Furthermore, our conceptualization of epistemological pluralism entails an a priori recognition that, in researching an SES, not only is the system behavior complex, but the values and goals that society holds for that system vary as well.

The existence, use, and appeal to multidisciplinary, interdisciplinary, and transdisciplinary research is recognition of the inadequacy of the existing organization of knowledge. This arrangement is limited in two primary ways (Thompson Klein 1996). First, as we have indicated, disciplines are often unwilling to move from their epistemic core. Second, the applied nature of much interdisciplinary work minimizes reflexivity regarding the role of epistemologies, the importance of process, the nature of uncertainty, etc. Such issues are perceived as inconsequential or secondary to the more immediate concern of producing "hard" knowledge. This may be further exacerbated when the research topic is problem based, and the need for information or resolution is urgent.

Epistemological pluralism seeks to avoid these traps by creating new ground that requires more than one epistemology and may enrich the theory of all involved rather than just one. As such, epistemological pluralism can be a form of transdisciplinary research. We should note, however, that our proposal should not be seen as being the same as Wilson's (1998) consilience argument for the unification of knowledge. This line of argumentation would lead to the eventual folding of multiple epistemologies under a single "best" view of nature as mechanistic. Instead, we argue that various insights and knowledge that separate epistemologies bring to bear on the problem may lead to a more complete understanding of the complexity of the situation, but that we can expect that the context and problems will change, prompting differing mixes of epistemologies.

With respect to the second limitation, epistemological pluralism starts with the assumption that ignoring the role of multiple ways of knowing, process, etc. in interdisciplinary research can torpedo efforts from the beginning. In fact, our proposal is an effort to build internal reflexivity into interdisciplinary and transdisciplinary research.

\section{EPISTEMOLOGICAL PLURALISM}

Many have noted how the disciplinary structure of knowledge itself inhibits fully interdisciplinary research (Daly and Cobb 1989, Cartwright 1999; Norton 2005). This is characterized by the practice of normal science as defined by Kuhn (1962), or science where "uncertainties are managed automatically, values are unspoken, and foundational problems unheard of" (Funtowicz and Ravetz 1993). Normal science has become less capable of addressing complex social-ecological interactions in particular (Gallopin et al. 2001), and less resilient to dramatic changes in the societal demand for knowledge (Lubchenco 1997) and to revelations from ongoing research that demand reconsideration of accepted theories. In an effort to move beyond a rigid knowledge structure that may fail to raise the most relevant questions and provide the most integrative solutions, we target both the social processes themselves and the values embedded in the production of knowledge as areas ripe for inquiry and advancement. Along these lines, we 
illustrate how a reorganization of academic resources may address the shortcomings associated with a rigid adherence to strictly disciplinary approaches, enhance the capacity for more fully integrative research and education, and provide practical alternatives to the unidirectional creation and transfer of knowledge (Stokes 1997, Roux et al. 2006). As an organizational and conceptual framework, we use Holling and Gunderson's (2002) complex adaptive cycle. We believe that this framework informs processes that operate at the scale of the individual researcher, the project team, as well as entire research institutions.

\section{How SESs Function}

Understanding any system's internal connections and the collective ability of these connections to respond to external forces or shocks is a challenge that faces all students of human behavior and environmental processes. The complex adaptive cycle provides a general blueprint for conceptualizing these phenomena and their dynamics. Inherent in the adaptive cycle approach is the concept of resilience, which is defined as "the amount of disturbance that can be sustained before a change in system control and structure occurs" (Holling and Gunderson 2002). Together, the resilience approach and the adaptive cycle are commonly used to illustrate the dynamics of social and ecological systems (Fig. 1).

Although cycles generally do not have a beginning or an end point, Walker and Salt (2006) choose the rapid growth phase, or $r$ phase, as their point of departure for describing the adaptive cycle. During the $r$ phase, systems experience a period of rapid growth as species (or social institutions) capture available resources and capitalize on new opportunities in the short term. During this phase, the system's components are loosely connected, its internal structure is weakly regulated, and it can be characterized by a high level of resilience.

The transition from the $\mathrm{r}$ phase to the conservation, or $\mathrm{K}$, phase proceeds over a larger time-scale. During this transition, capital accumulates and is stored, and the internal structure becomes more tightly regulated as long-term specialists outcompete short-term opportunists. As resources are sequestered, their range of potential use decreases. Connectivity between actors increases as they become entrenched in "mutually reinforcing relationships" (Walker and Salt 2006: 76). Ultimately, system variability declines and the system moves toward an increasingly rigid state.

In the $\mathrm{K}$ phase, highly connected resources render the system particularly vulnerable to outside shocks or disturbances. Following a shock, previously consolidated resources may be released through a process of "creative destruction" (Schumpeter 1950) during the release, or $\Omega$, phase. The internal structure and reinforcing relationships are broken apart and resources become available for new uses. In short, the system comes undone. This process can happen very quickly.

The result of the release phase is that accumulated capital resources become available to forge new relationships during the reorganization, or $\alpha$, phase. This is potentially a period of innovation, and one where novel combinations of resources can create new relationships that powerfully reshape the system's trajectory. However, strong legacies of former conditions may guide the system to a reorganization that maintains or recreates some or all of its former characteristics. Eventually these new or renewed relationships will themselves be tested as external conditions evolve (Walker and Salt 2006).

Alternative conceptualizations hold that resilience is more than simply a system's ability to maintain structure and function in the face of disturbance. It is also demonstrative of the system's ability to adapt and allow for continuous development (Folke 2006). According to this perspective, system resilience can be observed throughout the adaptive cycle. This interpretation, as well as the inclusion of panarchy and considerations of scale, is appropriate and fertile within the framework of epistemological pluralism presented below; however, these ideas will be set aside for future debate and examination as they lay outside the scope of this initial presentation.

Although the concepts of the adaptive cycle and the resilience approach have been developed primarily by ecologists, social scientists are increasingly applying this framework within the context of linked social-ecological systems to investigate resource-dependent communities (Adger 2000, Adger et al. 2005), emergency response networks (Allenby and Fink 2005), community-based property rights (Alcorn and Toledo 1998), pastoral herding (Niamir-Fuller 1998), power dynamics 
Fig. 1. The adaptive cycle (from Peeples et al. 2006).

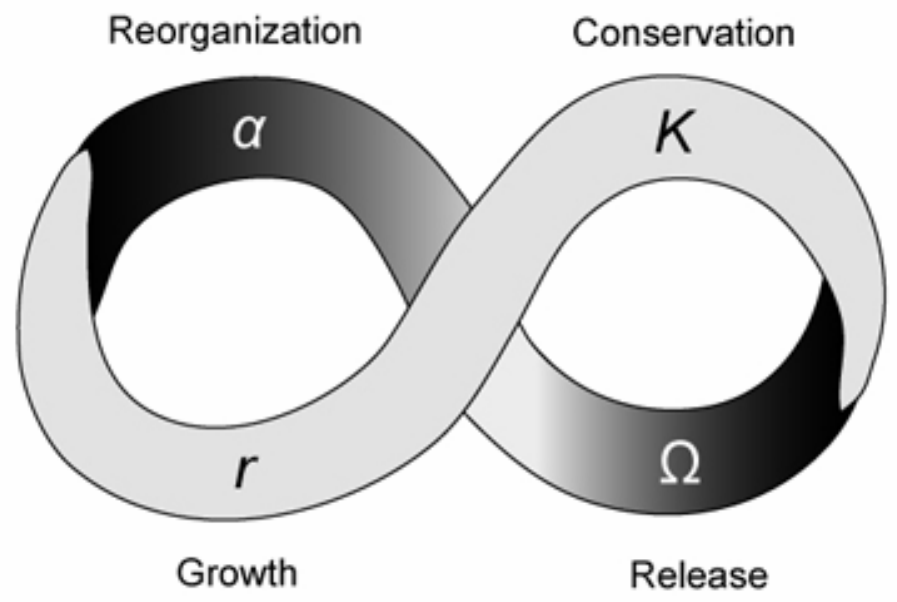

(Peterson 2000), stakeholder-led development (Walker et al. 2002), institutional robustness (Anderies et al. 2004), human perception (Janssen 2002), ancient societies (Redman and Kinzig 2003), and globalization (Armitage and Johnson 2006) to name just a few cases.

Our purpose here is not to apply social-ecological reasoning wholesale to the uniquely social problem of interdisciplinary research and education. Rather, we find the adaptive cycle as a useful conceptual framework for organizing and illustrating the dynamism of learning, institutional change, and knowledge production.

\section{Breakdown and Reorganization of Knowledge}

In many cases, research and education programs within the academy are currently entrenched in the conservation phase of the adaptive cycle, and considerable resources are expended to maintain the system in this state. The widespread and rigid codification of knowledge and the fortification of disciplinary boundaries further support this assertion (Norton 2005). These conditions suggest that our current system of knowledge production suffers from low institutional resilience, and consequently may be unable to adapt or respond to unanticipated calls for new information and greater understanding (Liu et al. 2007). These calls, which can be brought about by rapid change in complex relationships, can be seen as shocks (or disturbances) to the knowledge landscape. Those seeking to achieve transdisciplinary understanding of SESs are faced with the problem of how to reorganize knowledge production systems to encourage better innovative interdisciplinary research and education.

Drawing on the adaptive cycle as a general organizing framework, we propose a philosophical and practical reorganization of the ways in which interdisciplinary research and education are conducted. To guide this discussion, we present an alternative future shaped by four phases that are functionally similar to those contained in the adaptive cycle but thematically specific to the issue of knowledge production (Fig. 2). These new phases of knowledge production are: code degradation, epistemological pluralism, research coproduction, and knowledge coproduction.

Recognizing the risks associated with an academic system bounded in part by disciplinary approaches to knowledge production and the growing challenge for the academy to raise the most relevant questions and produce the most useful solutions, we propose a release of sufficient institutional resourcesintellectual, financial, and administrative-to 
Fig. 2. Epistemological pluralism and the adaptive cycle.

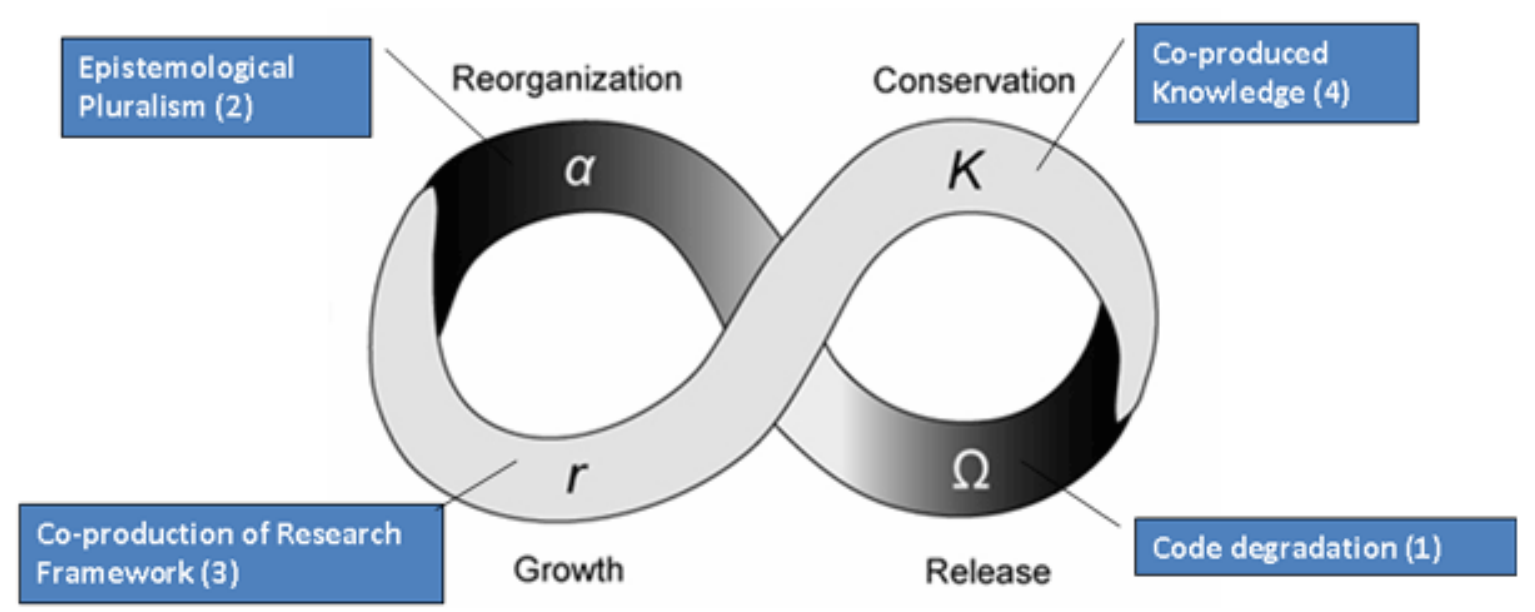

engage in the proposed reorganization guided by epistemological pluralism. In the $\Omega$ (or release or code-degradation) phase, these resources move beyond the rigid code that has held them in place and defined their relationships with each other. This process makes the newly accessible intellectual and financial resources available for novel reorganization and innovation in the next phase, epistemological pluralism. It is important to consider that during the code-degradation phase, the risk of resource loss is present. In the case of interdisciplinary research, the uncertainty associated with a reorganization of resources may cause financial sponsors and administrators to withdraw support.

As discussed earlier, reorganization of academic resources has typically been inhibited by epistemological sovereignty, entrenched financial and administrative flows, and limited access to high profile journals. This has involved the obfuscation of the role of values and cognitive aims in knowledge production, whether intentional or not. Epistemological pluralism, or the $\alpha$ phase, requires that these values and aims be actively engaged as newly available resources become reorganized. We would have traditional research and education programs reorganize under the guiding principle that there are multiple valid ways of knowing that each can deliver valuable information.
The concept of pluralism proceeds from empirical observations that the complexity of the natural world eludes complete representation by a single epistemological, theoretical, or investigative approach (Longino 2002). Reorganizing academic resources within a framework that acknowledges and respects epistemological pluralism and puts it at the center of the research enterprise, therefore, is a step toward greater, more integrative, understanding of complex social-ecological interactions. Central to the prospect of epistemological pluralism is the commitment to open and deliberate discussion and negotiation of researchers' values. We believe this stands in stark contrast to traditional approaches, which may proceed based on assumptions regarding collaborators' values.

To achieve this transformation, we propose that researchers, educators, and institutions commit to a process of social and scientific inquiry wherein values, aims, and parameters governing the validity of knowledge are continually negotiated in an iterative science cycle that is embedded in and travels through the larger adaptive cycle framework. The iterative science cycle involves learning, refinement, and action as values, epistemologies, and knowledges are continually negotiated (Fig. 3). It is within this iterative science cycle that the 
appropriateness and usefulness of a given epistemological perspective would be negotiated.

Although a full set of values and conceptions of the objective of inquiry may not be entirely shared, allowing for earnest discussion and negotiation is the first step toward a more fully integrated program of research and education that incorporates multiple perspectives, and challenges each actor's assumptions about project identity, data requirements, methodological approaches, and project goals.

Recognizing that such epistemic discussions are never fully settled or abandoned, the next phase in our cycle is the coproduction of a research or education framework during the $r$ phase. This phase is theoretically integrative and avoids the common tendency to privilege one epistemological approach or set of values over another. Through an iterative process of active engagement, mutual learning, and coordinated refinement, a blueprint for knowledge production can be jointly advanced. This approach has the potential to forge a coalition of perspectives and a convergence of contextual values for action by engaging multiple epistemologies, which may promote more relevant research and knowledge production in the $\mathrm{K}$ phase. This approach increases the likelihood of novel questions, answers, and trajectories that ultimately build social resilience into the academic enterprise, thus mitigating its exposure to risks associated with uncertainty and disturbance - at least in the short term. In the long term, the specific arrangement of values and epistemologies will ultimately yield to new inadequacy, requiring a new cycle of negotiation and knowledge production. The usefulness of a particular reorganization associated with a newly stabilized $\mathrm{K}$ phase is tested against experience.

We acknowledge the considerable costs implied by this approach. There are the usual drawbacks of interdisciplinary research, including lack of clear direction and methodology, lack of temporal and financial resources, institutional inertia, and barriers to publishing. Furthermore, the challenges associated with overhauling participants' perspectives, values, and basic assumptions cannot be overstated. Finally, we are not promoting an epistemic free-forall as resources are released and reorganized. We recognize that certain perspectives may be less critical for certain research projects or may be inappropriate in certain circumstances. Correspondingly, this provides opportunities for power asymmetries as new epistemological boundaries are erected or re-erected (MacMynowski 2007).

\section{CASE STUDIES: REORGANIZATION IN A SUB-FIELD AND AT SUB-ZERO}

The relevance of our proposal can be appreciated in the following cases studies, one with ties to a desert city, Phoenix, and the other based on experiences in the Arctic. Our discussion of urban ecology is of the reorganization of a field of study, whereas the Alaska case examines the practice of scientific inquiry and the way it is organized at a university. Furthermore, these case studies are not examples of epistemological pluralism; instead, they are meant to demonstrate how interdisciplinary efforts have been hampered by unexamined epistemological issues and how a closer examination of these issues is resulting in more integrative research.

\section{Urban Ecology}

Attempting to apply ecological concepts to human behavior, sociologists Robert Park and Peter Burgess first coined the term "urban ecology" in the 1930s (Grineski 2003). In the early 1950s, biologist Frank Evans (1951) recognized the unique challenges presented by the study of urban systems and called for closer cooperation between the biological and social sciences. Urban ecology now is the subject of a journal, Urban Ecosystems and two National Science Foundation-funded Integrated Graduate Research and Education Training (IGERT) programs, at Arizona State University and University of Washington, and forms the core of the only two urban National Science Foundation (NSF) Long-Term Ecological Research (LTER) stations in Baltimore, Maryland and Phoenix, Arizona (Pickett et al. 1997, Grimm et al. 2000, Alberti et al. 2003). As the discipline of ecology moves to study human-dominated areas (Palmer et al. 2004, Kareiva et al. 2007), urban ecology stands as one of the most promising frontiers of ecological research (Kingsland 2005).

In a review of urban ecological research, Young and Wolf (2006) examine the extent to which urban ecology has succeeded in addressing what they see as its three core commitments: (1) strengthen and expand ecological theory; (2) transdisciplinary research; and, (3) application, i.e., a link between science and policy. They find that, although urban ecology has been successful in contributing to ecological theory, research has not been sufficiently transdisciplinary nor has there been a clear link between urban ecological research and policy application. In fact, Young and Wolf (2006) find a 
Fig. 3. The iterative science cycle.

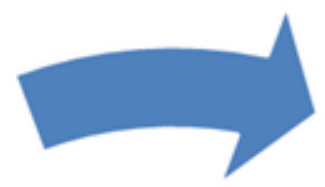

\section{Learning}

Refinement

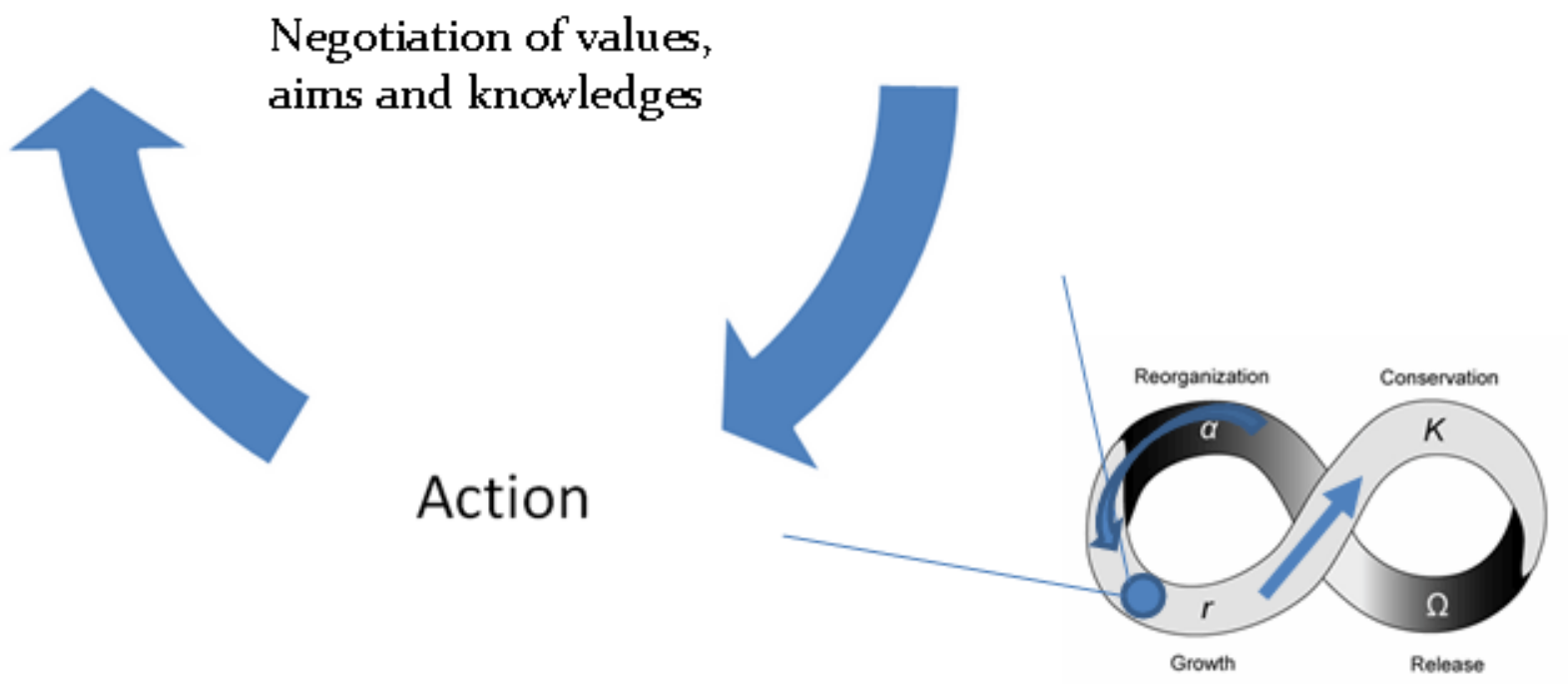

tendency toward a more disciplinary orientation. One could argue that an increasing focus on contributing to ecology as a discipline may come at the expense of connections to other relevant research in political ecology, planning, environmental justice, etc. Similarly, in a survey of the IGERT urban ecology faculty and students at ASU and UW, Grineski (2003) finds that natural scientists define urban ecology as the study of organisms in an urban area; i.e., ecology in the city. Many others argue that urban ecology is "the study of urban systems from an ecological perspective;" i.e., ecology of the city (Grimm et. al. 2000,Grineski 2003, Kinzig and Grove 2001).

In fact, we argue that this process can be best understood by looking at it in light of the adaptive cycle where "ecology in the city" studies developed and grew in importance in the 1970s through 1990s. What had been effectively developing as a study of species within city limits, in the late 1990s, was sent into the backloop of release $(\Omega)$ and reorganization $(\alpha)$ by the "shock or revolt" of the NSF issuing a call for two urban LTERs. Key to this call was a more comprehensive examination of cities as ecosystems with complex, interrelated sub-systems with objectives more consistent with expectation of policy and social scientific communities. In the reorganization of urban ecology, two trajectories emerged into their own $r$ phases. First, "ecology in the city" re-emerged into its own phase of growth and maturity, spawning such initiatives as "restoration ecology" (Marzluff et al. 2008). We consider the second a new trajectory representing a transformation to "ecology of the city" (Grimm et al. 2008). On this trajectory, a negotiation of 
approaches occurred as researchers in the newly established Baltimore and Phoenix LTERs sought to define their activities, and the newly granted IGERTs in urban ecology at the University of Washington and Arizona State University sought to develop an educational program that would facilitate this new research configuration. This process is being paralleled in Europe by the advancement of the long-term social-ecological research (LTSER) concept (Haberl et al. 2006), and in Asia and Latin America, through the establishment of an international LTER network with many urban nodes.

Urban ecology and the LTER program may be at a crossroads of sorts. For example, Haberl et al. (2006) argue that LTER projects have been dominated by natural science values as the determinant of the understanding of system behavior. They propose that the goal of LTER should be the production of knowledge that is useful for solving society's problems. If the aim is to contribute primarily to ecological theory, then urban ecology may be on the right path. If, however, the goal is to understand the behavior of urban ecological systems through interdisciplinary research that would be of direct value to society (which would, almost certainly, involve the use of and contribution to ecological theory), then a rethinking of the way urban ecological research is organized may be needed. To do so would require epistemological pluralism rather than a build-up to a $\mathrm{K}$ phase that gives epistemic sovereignty to ecology. This again highlights our point that the choice of approach - disciplinary, multidisciplinary, interdisciplinary, or transdisciplinary-depends on the research goals. In this case, interdisciplinarity or even multidisciplinary frameworks will meet the needs of an "ecology in the city" research goal, but if the aim is to understand "ecology of the city" then a more transdisciplinary approach is required (Fig. 4).

Although we do not argue that the urban ecological research being done under the original paradigm was not of value, we do see the transformation as being positive if the sustainable operation of cities is seen as an objective. However, even with the changes that have led to increasing numbers of social scientists being involved in LTER and other urban ecological research (Redman et al. 2004, Childers 2006, Gragson and Grove 2006) it seems clear that ecology still dominates the field-a case of epistemological sovereignty, for better or worse.
The activity of LTER social scientists continues to grow, with many LTER ecologists open to the change brought by an atmosphere of negotiation and exchange, or epistemological pluralism, in their own projects. Several studies emerging from the two urban LTERs demonstrate a new pluralism among disciplinary practitioners and a problem orientation with direct implications for community members. In Phoenix, it was found that neighborhoods subjected to more extreme episodes of heat stress were also those where residents lacked adequate social and material resources to cope with this threat (Harlan et al. 2006), whereas in Baltimore, collaborative teams suggested that riparian zones could serve as catalysts for ecological and socioeconomic revitalization (Groffman et al. 2003). Whether this type of focus on observational projects with community applications is a desirable development or not depends on your epistemological and disciplinary viewpoint, or a specific set of priorities and basic values. For instance, in discussing the future of urban ecological research, Shochat et al. (2006) call for a greater focus on studying the mechanisms that underlie urban ecological systems. This, we would argue, privileges a certain set of natural scientific values regarding desirable research questions and minimizes the importance of community engagement. Our own view is that, although science and society are best served by a diversity of approaches and the emergence of collaborative activities functioning within the guidelines of epistemological pluralism, this does not, however, obviate the need for continuing disciplinary research.

\section{Social-Ecological Systems Research in Alaska}

The practice of scientific inquiry in Alaskan SESs can be historically traced to periods of "pre-contact" in which indigenous peoples observed, assessed, and acted on knowledge that was based on cultural traditions and the need for ongoing subsistence harvesting. Science, culture, and resource management were integrated in all facets of life. After contact followed periods of imposed western institutions and social transformation, leading to release and reorganization. Among the significant forces of change in the state's history were the establishment of Alaskan statehood in 1959 and the Alaska Native Claims Settlement Act of 1971, which formally redefined (reorganization) many of the institutions that governed the use of natural 
Fig. 4. Transformation in urban ecology. As urban ecology entered the reorganization phase in "ecology in the city" following the call for long-term ecological research in urban areas, it transformed to "ecology of the city."

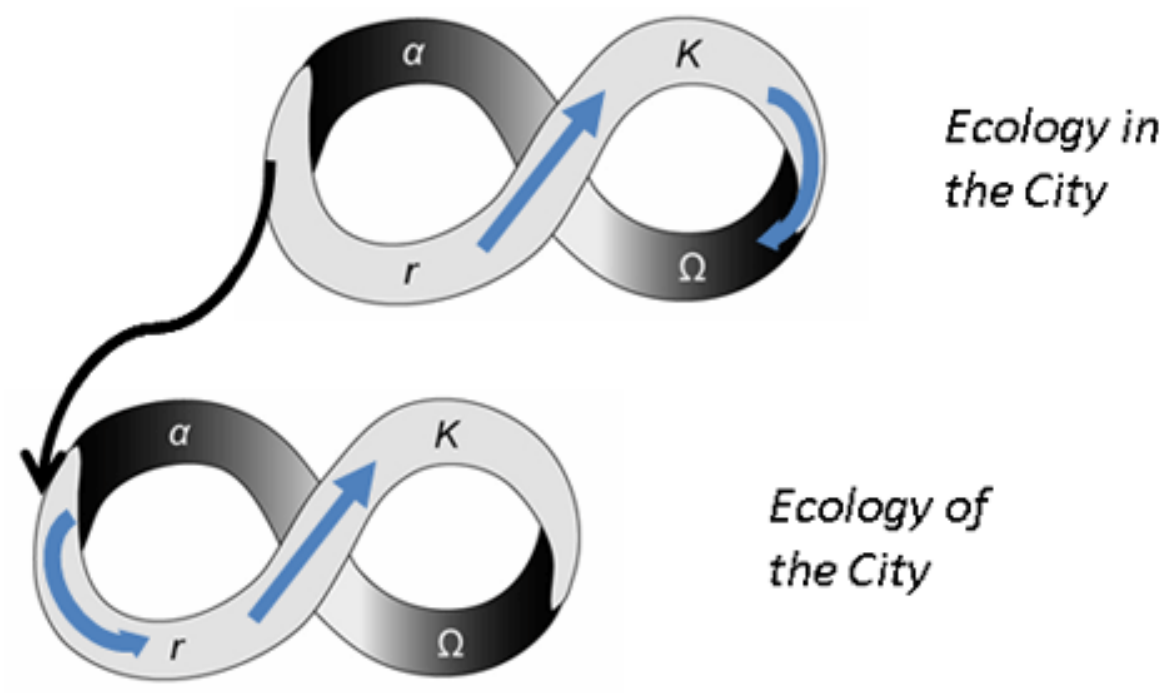

resources by rural indigenous communities. State and federal agencies assumed state ownership of wildlife and authority to regulate the harvest of fish and wildlife that formed an important nutritional and cultural base for these communities. These regulations were patterned after governmentcentered resource management approaches used elsewhere in the U.S. with little sensitivity to indigenous knowledge. Subsequent conflicts between state resource management and indigenous communities resulted. In several cases, imposed policies resulted in considerable hardship for indigenous peoples (e.g., the ban on spring waterfowl harvesting and the moratorium on native harvesting of bowhead whales). Both of these actions were taken based on scientific assumptions that later proved to be false and failed to consider indigenous knowledge in decision making and the importance of harvest to indigenous culture and livelihood.

These events were matched with other efforts during the second half of the 20th century to provide rural educational and social services and to westernize indigenous communities, speeding an ongoing process of cultural assimilation, again applying to indigenous Alaskans the U.S. "colonial" paradigm of appropriate education, housing, lifestyle, a single acceptable language (English), and social services ( $\mathrm{r}$ and $\mathrm{K}$ phases). Military developments during the Cold War, the discovery of big oil in 1969, and settlement of indigenous land claims contributed to rapid social and economic change. Most efforts to document and understand these changes had a single discipline orientation, despite the clear links between indigenous cultures and the environment in which they live (Nelson 1973, 1983, Kofinas et al. 2002, Natcher et al. 2007).

Like most universities, the University of Alaska Fairbanks (UAF) is organized into disciplinary departments whose scholarship is based on separate epistemologies, leading to largely disciplinary programs of education and research. Although early research enterprises at UAF were holistic in approach, by the 1970s, many of these efforts were replaced with the kinds of silo science found in other parts of the country. Thus, the arenas of resource management, social services, and academics in Alaska have been largely dominated by epistemological approaches borrowed from elsewhere and applied with minor modifications to Alaska. 
Today's rapid social-ecological changes, including climate change, in Alaska (Krupnik and Jolly 2002, Artic Climate Impact Assessment (ACIA) 2005, Hinzman et al. 2005) have challenged the capacity of disciplinary-based science and management to understand their sources, emergent dynamics, and implications to society. An increased awareness of the inadequacies of discipline-based science to document and understand change and its implications has coincided with an increased sophistication of Alaskan Natives to invoke the legitimacy and utility of indigenous knowledge. In this way, a system of knowledge production, based on the segregation of epistemologies, proved deficient and ripe for reorganization and release. Resistance to change has led to increased rigidity (conservation) in some realms and to reorganization in a different epistemological context in others, both of which are briefly illustrated below with two examples.

The failure of conventional resource management to meet the needs of local indigenous communities gave rise to a variety of arrangements for managing resources in Alaska, each dominated by a single epistemology. Wildfires are managed largely by agencies according to regulations developed to address wildfire issues in "the lower 48," with minimal input from communities. In contrast, some wildlife populations are comanaged by agencies and communities, with the balance of power between competing epistemologies varying substantially from case to case. For other resources, such as the gathering of berries and other country foods, local and traditional institutions have largely governed patterns of use. In each case, a single epistemology has predominated.

Within the UAF, educational programs exhibited a variety of responses to the rapid social, political, and environmental changes that occurred in Alaska in the late 20th century, including (1) the development of greater disciplinary depth in some fields such as geophysics and Alaska Native languages; (2) formation of an indigenous studies curriculum that applied university resources to more traditional modes of knowledge transfer; and (3) interdisciplinary programs such as the Resilience and Adaptation Program that trained graduate students to integrate the cultural, economic, and ecological bases of sustainability. The academic reorganization that led to this graduate program contributed to a university-wide growth of academic interest in sustainability ( $\mathrm{r}$ phase). However, it initially achieved limited epistemological pluralism because of the inexperience of disciplinary faculty and students within its interdisciplinary arena. Initial thesis projects generally privileged a single epistemology that was informed by other perspectives provided by the program, giving rise to interdisciplinary products. Increasing familiarity and experience with multiple epistemologies has given rise to a series of experiments, many of which show greater epistemological pluralism, including a new PhD program in Natural Resources and Sustainability. The Resilience and Adaptation Program was later redesigned around transdisciplinary courses whose core elements were socialecological sustainability, adaptive capacity, resilience, and integrative assessment rather than traditional disciplines. This led to discussions and projects that were issue and solution focused and more holistic in orientation than earlier courses. Similar epistemological reorganizations occurred within research, as new partnerships developed among faculty, students, and stakeholders in which local communities played a leading role in defining research goals and context rather than simply being the objects of study. This led to more rapid development of trust and deeper insights than had occurred in more traditional research frameworks.

The main message from this case study is that rapid change spurred several societal and academic responses, ranging from more deeply entrenched disciplinarity (continued $\mathrm{K}$ phase) to experiments requiring epistemological pluralism. These later efforts included partial successes that themselves become seeds for subsequent adaptive cycles of epistemological experimentation and recombination.

\section{CONCLUSION}

The prospect of a new and more richly integrative approach to research and education is one that the academy as well as society must embrace. The risks associated with inaction at this critical juncture overwhelmingly outweigh the concerns that arise from the uncertainty of future steps. In this paper, we have purposefully avoided the provision of a specific action agenda or rigid outline for successful interdisciplinary research. To do so would be to contradict one of our central points-that a reorganization of multiple, potentially equally valid ways of knowing requires a negotiation governed by the specifics of the question and the composition of the research team. Although individual 
disciplines are well positioned to examine certain areas of concern, many inflexible and entrenched epistemological cultures have generated strictly parochial inquiries of expansive, complex systems, such as SESs. One goal of this paper has been to highlight the relevance of accommodating and integrating disparate values, epistemologies, and knowledges toward a more robust understanding of complex issues-issues of sustainability that bear considerable import in our rapidly changing world.

With this paper, students and faculty from six separate backgrounds have come together to propose that (1) there are multiple ways knowing present in a given research context that may be equally valuable; (2) integration of this plurality results in a more thorough understanding of complex systems; (3) the adaptive cycle provides a useful framework for navigating the production of knowledge; and (4) the application of this framework is relevant across scales. We believe that a reorganization of resources shaped by epistemological pluralism can enhance our capacity in the academy as well as society writ large to manage global socioecological challenges, and consequently engender a more resilient future.

Responses to this article can be read online at:

http://www.ecologyandsociety.org/voll3/iss2/art46/responses/

\section{Acknowledgments:}

The authors thank Shade T. Shutters and Tischa A. Muñoz-Erickson for their valuable insights in developing and expanding on these ideas, as well as Stuart G. Fischer for his insightful comments on the manuscript. We also thank everyone who participated in and organized the National Science Foundation (NSF)-sponsored Conference for Sustainability IGERTs at the University of Alaska Fairbanks in October 2007. Without the stimulating discussions we all took part in there, this paper would never have been written. This material is based on work supported in part by the NSF IGERT Grant No. 0504248 in Urban Ecology to the Global Institute of Sustainability at Arizona State University; IGERT Grant No. 0333193 in Population and Environment to the Carolina Population Center at the University of North Carolina at Chapel Hill; IGERT Grant No. 0630050 in Resilience and Adaptation to the University of
Alaska Fairbanks; and IGERT Grant No. 0549407 in CHANGE at the University of WisconsinMadison. Any opinions, findings, and conclusions or recommendation expressed in this material are those of the authors and do not necessarily reflect the views of the NSF. Finally, the authors thank two anonymous reviewers for their insightful comments which have greatly improved the paper.

\section{LITERATURE CITED}

Adger, W. N. 2000. Social and ecological resilience: are they related? Progress in Human Geography $\mathbf{2 4}$ (3):347-364.

Adger, W. N., T. P. Hughes, C. Folke, S. R. Carpenter, and J. Rockstrom. 2005. Socialecological resilience to coastal disasters. Science 309(5737):1036-1039.

Alberti, M., J. M. Marzluff, E. Shulenberger, G. Bradley, C. Ryan, and C. Zumbrunnen. 2003. Integrating humans into ecology: opportunities and challenges for studying urban ecosystems. Bioscience 53(12):1169-1179.

Alcorn, J. B., and V. Toledo. 1998. Resilient resource management in Mexico's forest ecosystems. Pages 216-249 in F. Berkes and C. Folke, editors. Linking social and ecological systems: management practices and social mechanisms for building resilience. Cambridge University Press, New York, New York, USA.

Allenby, B., and J. Fink. 2005. Toward inherently secure and resilient societies. Science 309 (5737):1034-1036.

Anderies, J. M., M. A. Janssen, and E. Ostrom. 2004. A framework to analyze the robustness of social-ecological systems from an institutional perspective. Ecology and Society 9(1): 18. [online] URL: http://www.ecologyandsociety.org/vol9/iss 1/ art18/.

Arctic Climate Impact Assessment (ACIA). 2005. Arctic climate impact assessment. Cambridge University Press, Cambridge, UK.

Armitage, D., and D. Johnson. 2006. Can resilience be reconciled with globalization and the 
increasingly complex conditions of resource degradation in Asian coastal regions? Ecology and Society 11(1): 2. [online] URL: http://www.ecology andsociety.org/vol11/iss1/art2/.

Cartwright, N. 1999. The dappled world : a study of the boundaries of science. Cambridge University Press, New York, New York, USA.

Childers, D. L. 2006. A synthesis of long-term research by the Florida Coastal Everglades LTER Program. Hydrobioliogia 569:531-544.

Collins, J., A. Kinzig, N. B. Grimm, W. F. Fagan, D. Hope, J. Wu, and E. T. Borer. 2000. A new urban ecology. American Scientist 88:416-425.

Committee on Facilitating Interdisciplinary Research, Committee on Science, Engineering, and Public Policy, National Academy of Sciences, National Academy of Engineering, and Institute of Medicine of the National Academies. (CoFIR et al.) 2005. Facilitating interdisciplinary research. National Academies Press, Washington, D.C., USA.

Daly, H., and J. Cobb, Jr. 1989. For the common good: redirecting the economy toward community, the environment, and a sustainable future. Beacon Press, Boston, Massachusetts, USA.

Eigenbrode, S. D., M. O’Rourke, J. D. Wulfhorst, D. M. Althoff, C. S. Goldberg, K. Merrill, W. Morse, M. Nielsen-Pincus, J. Stephens, L. Winowiecki, and N. A. Bosque-Perez. 2007. Employing philosophical dialogue in collaborative science. BioScience 57(1):55-64.

Evans, F. C. 1951. Symposium on viewpoints, problems, and methods of research in urban areas biology and urban areal research. The Scientific Monthly July:37-38.

Folke, C. 2006. Resilience: the emergence of a perspective for social-ecological systems analyses. Global Environmental Change 16(3):253-267.

Funtowicz, S., and J. Ravetz. 1993. Science for the post-normal age. Futures 25(7):735-755.

Gallopin, G. C., S. Funtowicz, M. O'Connor, and J. Ravetz. 2001. Science for the twenty-first century: from social contract to scientific core. International Social Science Journal 53(2):219229.
Gragson, T. L., and J. M. Grove. 2006. Social science in the context of the long term ecological research program. Society and Natural Resources 19(2):93-100.

Grimm, N. B., S. H. Faeth, N. E. Golubiewski, C. L. Redman, J. Wu, X. Bai, and J. M. Briggs. 2008. Global change and the ecology of cities. Science 319:756-760.

Grimm, N. B., J. M. Grove, S. T. A. Pickett, and C. L. Redman. 2000. Integrated approaches to long-term studies of urban ecological systems. BioScience 50(7):571-584.

Grineski, S. E. 2003. Commentary: toward an integrative urban ecology: voices from the IGERTs. Bulletin of the Ecological Society of America October:200-205.

Groffman, P. M., D. J. Bain, L. E. Band, K. T. Belt, G. S. Brush, J. M. Grove, R. V. Pouyat, I. C. Yesilonis, and W. C. Zipperer. 2003. Down by the riverside: urban riparian ecology. Frontiers in Ecology and the Environment 1(6):315-321.

Haberl, H., V. Winiwarter, K. Andersson, R. U. Ayres, C. Boone, A. Castillo, G. Cunfer, M. Fischer-Kowalski, W. R. Freudenburg, E. Furman, R. Kaufmann, F. Krausmann, E. Langthaler, H. Lotze-Campen, M. Mirti, C. L. Redman, A. Reenberg, A. Wardell, B. Warr, and H. Zechmeister. 2006. From LTER to LTSER: conceptualizing the socioeconomic dimension of long-term socio-ecological research. Ecology and Society 11(2): 13. [online] URL: http://www.ecolog yandsociety.org/vol11/iss2/art13/.

Harlan, S. L., A. Brazel, L. Prashad, W. L. Stefanov, and L. Larsen. 2006. Neighborhood microclimates and vulnerability to heat stress. Social Science and Medicine 63:2847-2863.

Healy, S. 2003. Epistemological pluralism and the "politics of choice." Futures 35(7):689-701.

Hinzman, L. D., N. D. Bettez, W. R. Bolton, F. S. Chapin, III, M. B. Dyurgerov, C. L. Fastie, B. Griffith, R. D. Hollister, A. Hope, H. P. Huntington, A. M. Jensen, G. J. Jia, T. Jorgenson, D. L. Kane, D. R. Klein, G. Kofinas, A. H. Lynch, A. H. Lloyd, A. D. McGuire, F. E. Nelson, M. Nolan, W. C. Oechel, T. E. Osterkamp, C. H. Racine, V. E. Romanovsky, R. S. Stone, D. A. 
Stow, M. Sturm, C. E. Tweedie, G. L. Vourlitis, M. D. Walker, D. A. Walker, P. J. Webber, J. Welker, K. S. Winker, and K. Yoshikawa. 2005. Evidence and implications of recent climate change in northern Alaska and other arctic regions. Climatic Change 72(3):251-298.

Holling, C. S., and L. Gunderson. 2002. Resilience and adaptive change. Pages 25-62 in L. Gunderson and C. S. Holling, editors. Panarchy: understanding transformations in human and natural systems. Island Press, Washington, D.C., USA.

Janssen, M. A. 2002. A future of surprises. Pages 241-260 in L. H. Gunderson and C. S. Holling, editors. Panarchy: understanding transformations in human and natural systems. Island Press, Washington, D.C., USA.

Kareiva, P., S. Watts, R. McDonald, and T. Boucher. 2007. Domesticated nature: shaping landscapes and ecosystems for human welfare. Science 316(5833): 1866-1869.

Kingsland, S. E. 2005. The evolution of American ecology, 1890-2000. Johns Hopkins University Press, Baltimore, Maryland, USA.

Kinzig, A. P., and J. M. Grove. 2001. Urbansuburban ecology. Encyclopedia of Biodiversity 5:733-745.

Kofinas G. P., and Communities of Aklavik, Old Crow, and Fort McPherson. 2002. Community contributions to ecological monitoring: knowledge co-production in the U.S.-Canada arctic borderlands. Pages 54-91 in I. Krupnik and D. Jolly editors. The earth is faster now: indigenous observations of Arctic environmental change. Arctic Research Consortium of the United States, Fairbanks, Alaska, USA.

Krupnik, I., and D. Jolly, editors. 2002. The earth is faster now: indigenous observations of Arctic environmental change. Arctic Research Consortium of the United States, Fairbanks, Alaska, USA.

Kuhn, T. S. 1962. The structure of scientific revolutions. University of Chicago Press, Chicago, Illinois, USA.

Lee, K. N. 1993. Compass and gyroscope: integrating science and politics for the environment. Island Press, Washington, D.C., USA.
Liu, J., T. Dietz, S. R. Carpenter, M. Alberti, C. Folke, E. Moran, A. N. Pell, P. Deadman, T. Kratz, J. Lubchenco, E. Ostrom, Z. Ouyang, W. Provencher, C. L. Redman, S. H. Schneider, and W. W. Taylor. 2007. Complexity of coupled human and natural systems. Science 317(5844):15131516.

Longino, H. E. 1990. Science as social knowledge. Princeton University Press, Princeton, New Jersey, USA.

Longino, H. E. 2002. The fate of knowledge. Princeton University Press, Princeton, New Jersey, USA.

Lubchenco, J. 1997. Entering the century of the environment: a new social contract for science. Science 279:491-497.

MacMynowski, D. P. 2007. Pausing at the brink of interdisciplinarity: power and knowledge at the meeting of social and biophysical science. Ecology and Society 12(1):20. [online] URL: http://www.ec ologyandsociety.org/vol12/iss1/art20/.

Marzluff, J. M., E. Shulenberger, W. Endlicher, M. Alberti, G. Bradley, C. Ryan, C. ZumBrunnen, and U. Simon, editors. 2008. Urban ecology: an international perspective on the interaction between humans and nature. Springer, New York, New York, USA.

Miller, C., and P. Erickson. 2006. The politics of bridging scales and epistemologies: science and democracy in global environmental governance. Pages 297-314 in W. V. Reid, F. Berkes, T. Wilbanks, and D. Capistrano, editors. Bridging scales and knowledge systems: concepts and applications in ecosystem assessment. Island Press, Washington D.C., USA.

Natcher, D. C., M. Calef, O. Huntington, S. Trainor, H. P. Huntington, L. DeWilde, S. Rupp, and F. S. Chapin, III. 2007. Factors contributing to the cultural and spatial variability of landscape burning by native peoples of interior Alaska. Ecology and Society 12(1):7. [online] URL: http:// www.ecologyandsociety.org/vol12/iss1/art7/.

Nelson R. K. 1973. Hunters of the northern forest. University of Chicago Press, Chicago, Illinois, USA. 
Nelson R. K. 1983. Make prayers to the raven: a Koyukan view of the northern forest. University of Chicago Press, Chicago, Illinois, USA.

Niamir-Fuller, M. 1998. The resilience of pastoral herding in Sahelian Africa. Pages 250-284 in F. Berkes and C. Folke, editors Linking social and ecological systems: management practices and social mechanisms for building resilience. Cambridge University Press, New York, New York, USA.

Norton, B.G. 2005. Sustainability: a philosophy of adaptive ecosystem management. University of Chicago Press, Chicago, Illinois, USA.

Palmer, M., E. Bernhardt, E. Chornesky, S. Collins, A. Dobson, C. Duke, B. Gold, R. Jacobson, S. Kingsland, R. Kranz, M. Mappin, M. L. Martinez, F. Micheli, J. Morse, M. Pace, M. Pascual, S. Palumbi, O. J. Reichman, A. Simons, A. Townsend, and M. Turner. 2004. Ecology for a crowded planet. Science 304 (5675):1251-1252.

Peeples, M. A., C. M. Barton, and S. Schmich. 2006. Resilience lost: intersecting land use and landscape dynamics in the prehistoric southwestern United States. Ecology and Society 11(2): 22. [online] URL: http://www.ecologyandsociety.org/voll1/ iss2/art22/.

Peterson, G. D. 2000. Political ecology and ecological resilience: an integration of human and ecological dynamics. Ecological Economics 35 (3):323-336.

Petts, J., S. Owens, and H. Bulkeley. 2008. Crossing boundaries: interdisciplinarity in the context of urban environments. Geoforum 39 (2):593-601.

Pickett, S. T. A., W. R. Bruch, Jr., S. D. Dalton, and T. W. Foresman. 1997. Integrated urban ecosystem research. Urban Ecosystems 1:183-184.

Redman, C. L., J. M. Grove, and L. H. Kuby. 2004. Integrating social science into the long-term ecological research (LTER) network: social dimensions of ecological change and ecological dimensions of social change. Ecosystems 7(2):161171
Redman, C. L., and A. P. Kinzig. 2003. Resilience of past landscapes: resilience theory, society, and the longue durée. Conservation Ecology 7(1): 14. [online] URL: http://www.ecologyandsociety.org/vol7/ iss1/art14/.

Reich, S. M., and J. A. Reich. 2006. Cultural competence in interdisciplinary collaborations: a method for respecting diversity in research partnerships. American Journal of Community Psychology 38(1-2):51-62.

Rescher, N. 2003. Epistemology: an introduction to the theory of knowledge. State University of New York Press, Albany, New York, USA.

Roux, D. J., K. H. Rogers, H. C. Biggs, P. J. Ashton, and A. Sergeant. 2006. Bridging the science-management divide: moving from unidirectional knowledge transfer to knowledge interfacing and sharing Ecology and Society 11(1): 4. [online] URL: http://www.ecologyandsociety.org/vol11/iss1/art4/

Schumpeter, J. 1950. Capitalism, socialism and democracy. Harper and Row, New York, New York, USA.

Shochat, E., P. S. Warren, and S. H. Faeth. 2006. Future directions in urban ecology. TRENDS in Ecology and Evolution 21(12):661-662.

Stokes, D. 1997. Pasteur's quadrant: basic science and technological innovation. Brookings Institution Press, Washington, D.C., USA.

Thompson Klein, J. 1996. Crossing boundaries: knowledge, disciplinarities, and interdisciplinarities. University Press of Virginia, Charlottesville, Virginia, USA.

Walker, B., S. Carpenter, J. M. Anderies, N.Abel, G. Cumming, M. Janssen, L. Lebel, J. Norberg, G.D.Peterson, and R.Pritchard.2002. Resilience management in social-ecological systems: a working hypothesis for a participatory approach. Conservation Ecology 6(1): 14. [online] http://www .ecologyandsociety.org/vol6/iss1/art14/.

Walker, B., and D. Salt. 2006. Resilience thinking: sustaining ecosystems and people in a changing world. Island Press, Washington, D.C., USA. 
Wilson, E. O. 1998. Consilience: the unity of knowledge. Vintage Books, New York, New York, USA.

Wohl, R. 1955. Some observations on the social organization of interdisciplinary social science research. Social Forces 33:374-383.

Young, R. F., and S. A. Wolf. 2006. Goal attainment in urban ecology research: a bibliometric review 1975-2004. Urban Ecosystems 9(3):179-193.

[ $\dagger$ In fact, this paper was spawned from an interdisciplinary discourse among faculty and students at the Conference for Sustainability IGERTs (C4SI), which was a 3-day conference at the University of Alaska Fairbanks for IGERT PhD fellows in programs related to sustainability and the study of social-ecological systems. Among the themes that emerged repeatedly were the barriers, both practical and philosophical, to interdisciplinary research. 